\title{
Identifying the reasons for delayed presentation of Pakistani breast cancer patients at a tertiary care hospital
}

This article was published in the following Dove Medical Press journal: Cancer Management and Research

\author{
Faisal Gulzar ${ }^{1,2}$ \\ Muhammad Shoaib Akhtar \\ Rafshan Sadiq ${ }^{3}$ \\ Sajid Bashirl \\ Sajida Jamil ${ }^{2}$ \\ Shahid Mahmood Baig ${ }^{4,5}$ \\ 'Department of Pharmacology, \\ College of Pharmacy, University of \\ Sargodha, Sargodha, Punjab, Pakistan; \\ 2Department of Pharmacology, \\ Faculty of Pharmacy, The University \\ of Lahore, Lahore, Punjab, Pakistan; \\ ${ }^{3}$ Punjab Institute for Nuclear \\ Medicines (PINUM) Cancer Hospital, \\ Faisalabad, Punjab, Pakistan; ${ }^{4}$ Human \\ Molecular Genetics Laboratory, \\ Health Biotechnology Division, \\ National Institute for Biotechnology \\ and Genetic Engineering (NIBGE), \\ Faisalabad, Punjab, Pakistan; ${ }^{5}$ Pakistan \\ Institute of Engineering and Applied \\ Sciences (PIEAS), Islamabad, Punjab, \\ Pakistan
}

Background: Delay in seeking health care by breast cancer patients is associated with advanced stage of disease at presentation and poor survival rates. This study aimed to identify the reasons for delayed presentation and their association with various sociodemographic variables.

Methods: A total of 200 female patients with abnormal clinical findings, ie, lump or palpable mass, were consecutively invited for this study. Diagnostic delay was defined as a consultation with a health care provider more than 3 months from the appearance of the first symptoms. Sociodemographic variables, presenting symptoms, knowledge about diseases and its symptoms, time between seeking medical attention after appearance of symptoms and causes of delayed presentation were investigated. Chi-squared and logistic regression tests for significance and associations were used. Results: Among 125 women with breast cancer fulfilling the inclusion criteria, aged 24-75 years, $88.8 \%$ ( $n=111)$ presented late ( $\geq 3$ months) and 59\% presented with advanced stage of disease (stage III/IV). The majority (65.6\%) were older than 40 years of age, $99.2 \%$ were married, $60.8 \%$ had $<8$ years of education, $67.2 \%$ had poor social status, and $64.8 \%$ had a negative family history of any cancer type. Almost all patients (96\%) complained about the presence of a painless lump in their breast. Ignorance of disease or the presence of painless lumps in the breast and low financial resources for therapy $(81.1 \%)$ were the main variables associated with delayed presentation. Educational factors $(P<0.001$, OR 4.682) and social status $(P<0.001$, OR 1.8) were also associated with delayed presentation.

Conclusion: Our study highlighted the variables associated with delayed presentation in Pakistani breast cancer patients. A significant number of patients presented late owing to misconceptions and poor knowledge about the disease and its symptoms, while illiteracy and poor social status were the major contributing factors for delayed presentation, resulting in an advanced presentation of disease and ultimately a decreased survival rate.

Keywords: breast cancer, painless lump, social status, illiteracy, survival rate

\section{Introduction}

Breast cancer is the most prevalent cancer type in females worldwide. According to the GLOBOCAN report, about 2.08 million new breast cancer cases were diagnosed in 2018 , accounting for $24.2 \%$ of all cancer cases. It is the leading cause of mortality, contributing to $15 \%$ of total cancer deaths specifically in less developed countries. ${ }^{1}$ Previous studies have also endorsed that the incidence of breast cancer is higher in developed counteries. ${ }^{2,3}$ However, recent evidence suggests that there has been an alarming increase in both incidence and mortality rate in low- and middle-income countries. ${ }^{1,4-10}$ This may be due to different factors, such as educational level, lack of awareness and knowledge about the disease and its symptoms, and the unavailability of mammography facilities and breast cancer screening programs in a country; and 
the prevalence of risk factors such as precancerous lesions, reproductive factors (eg, age at menarche and childbirth, lack of breastfeeding and late menopause), family history, obesity, inappropriate dietary habits, hormonal therapy, physical inactivity, use of oral contraceptives, alcohol consumption, genetic predisposition, exposure to ionizing radiation, change in immune status and host vulnerability. ${ }^{11-13}$

In Pakistan, breast cancer is more common in young females, in contrast to the West, where it occurs after the age of 60 years, on average. ${ }^{14}$ The age-related incidence rate of breast cancer affecting Pakistani females is almost 50.1/100,000 per year. ${ }^{15}$ The probability is that one out of every nine Pakistani women will develop breast cancer during her lifetime. ${ }^{16}$ Pakistan has the highest incidence and mortality rates of breast cancer, with incidence and mortality rates $>5.2$ times and $>2.8$ times higher, respectively, than the rates within the rest of Asia. Moreover, when compared with neighboring countries, ie, India and Iran, the incidence rate was $>2.5$ times higher in Pakistan. ${ }^{5,17}$ The lack of a national cancer registry in Pakistan is the main reason of low quality incidence, mortality and prevalence data for the country. According to facility- based studies and projections, the number of new cases is estimated between 34,038 and 90,000 cases and mortality around 16,232 deaths in $2017 .^{8,19}$

The literature has suggested that a lack of awareness and knowledge is associated with delayed presentation, and this delay may be attributed to personal, sociocultural and economic factors. ${ }^{17,20}$ Although personal factors such as age, marital status and medical history, along with economic factors such as occupation, monthly income and treatment cost, are not amendable, socio-cultural variables such as people's knowledge and assumptions about a disease, its signs and symptoms, and the perceived stigma associated with the disease, eg, that it is incurable and life-threatening, are adaptable. ${ }^{21}$ Procrastination results in an enlarged tumor size, advanced stage of disease and poorer prognosis, which ultimately contribute toward increasing morbidity, disability and mortality. Patients with delayed presentation have lower 5 -year survival rates than those with early presentation, at $12 \%$ and $88 \%$, respectively. ${ }^{22}$

In Pakistan, more than $50 \%$ of patients present at an advanced stage of disease, ie, stage III or IV. ${ }^{23}$ The duration of delay in seeking medical aid after the appearance of breast cancer symptoms can be reduced by identifying possible factors contributing to the delay, which could improve early diagnosis of the disease, at a less advanced stage, meaning a better prognosis and ultimately improved survival rates. ${ }^{24}$

\section{Material and methods}

\section{Study setting}

This study was conducted at the Punjab Institute of Nuclear Medicine (PINUM) Cancer Hospital, Faisalabad, Punjab, Pakistan. Faisalabad, an industrial hub, is the third most populous city of Pakistan, with an approximate population of more than 7.8 million $(7,874,790)$, as indicated by the 2017 census. ${ }^{25}$ PINUM is a tertiary cancer hospital, established by the Pakistan Atomic Energy Commission (PAEC), that has served the people of Faisalabad and its periphery since 1996. It has well-reputed diagnostic laboratories, along with chemotherapy and radiotherapy facilities for various cancers. For early detection, the outpatient department (OPD) has recently started a breast cancer clinic day program, along with mammography, ultrasound and biopsy facilities. According to the hospital records, about 1,624 breast cancer patients were diagnosed in the OPD from 2011 to 2016.

\section{Sample size}

The minimum sample size, calculated through the Raosoft ${ }^{\circledR}$ sample-size calculator, was 111 breast cancer patients. ${ }^{26}$ The population was taken as 331 (maximum number of patients diagnosed in 2015, according to hospital records). For this, the power was taken as $80 \%$, with a $50 \%$ response distribution with $90-95 \% \mathrm{CI}$ and $5-10 \%$ of alpha margin, respectively.

$$
n=N \frac{x}{(N-1) E^{2}+x}
$$

where $N$ is population size, $x$ is the confidence interval and $E$ is the alpha error. With an added $12 \%$ contingency for nonresponse and inappropriate responses, the final sample was calculated to be 125 patients. This sample size was confirmed using G*Power version 3.1.9.2 (Düsseldorf, Germany). The $F$ test (multivariate analysis of variance special effects and interaction) was performed by considering a power of $80 \%$ and 0.05 margin of error. ${ }^{27}$

\section{Identification of participants}

All registered women with breast cancer from January 2011 were consecutively invited to participate in this study. The population sample included patients who were diagnosed, received chemotherapy or visited PINUM cancer hospital for either follow-up or consultation up to April 2017. None of the patients was pregnant or lactating. All consenting patients, regardless of their age and marital status, along with histopathological reports that confirmed the presence of disease, were included in the study. Females with no histological evidence of invasive breast cancer, or who had psychiatric 
comorbidities impairing their personal ability, amnesia, noncancerous lumps or uncooperative behavior, and those who have not given written consent for their participation, were excluded from the study. Exclusion and inclusion criteria are summarized in Figure 1.

\section{Data collection}

A questionnaire with instructions for data collection and orientation about the study design, in the local language (ie, Urdu or Punjabi), was given to patients, after which they were invited to participate in the study. A semi-structured, faceto-face interview was carried out with each patient, which lasted for 30-40 minutes (mean 26 minutes) per session. The interview included questions on demographic factors, including age, educational and income level, family history of cancer or breast cancer, etc. The patients were also asked to specify the first presenting or observed symptoms of the disease (ie, painless lump, breast pain, etc). Knowledge about breast cancer risk factors was assessed by asking open-ended questions, while possible reasons for their delayed presentation were also documented. In addition, histopathological reports were examined to confirm the diagnosis of invasive disease, along with receptor status and stage of cancer. A univocal numeric identifier for anonymization was assigned to each study participant for data analysis.

\section{Statistical analysis}

Descriptive and chi-squared tests were performed to determine statistical significance between the studied variables, while logistic regression was used to find associations between the studied variables and delayed presentation. A $P$-value of $<0.05$ was considered significant for all tests. Statistical analyses were conducted using SPSS software version 23 (IBM Corporation, Armonk, NY, USA).

\section{Ethical considerations}

The study design and questionnaire were evaluated and approved by the institutional ethical review committee board of the National Institute for Biotechnology and Genetic Engineering (NIBGE), Faisalabad, Punjab (reference number 102/14). The whole study was conducted in accordance with the Declaration of Helsinki. Written informed consent was obtained from each patient to access her medical records, blood sampling for genotype analysis and authorization to use her personal/genomic data for publication.

\section{Results \\ Selection of participants}

Overall, 200 patients were interviewed during the study period and 75 patients were excluded from the study based on exclusion criteria, ie, missing medical records $(n=15)$, having

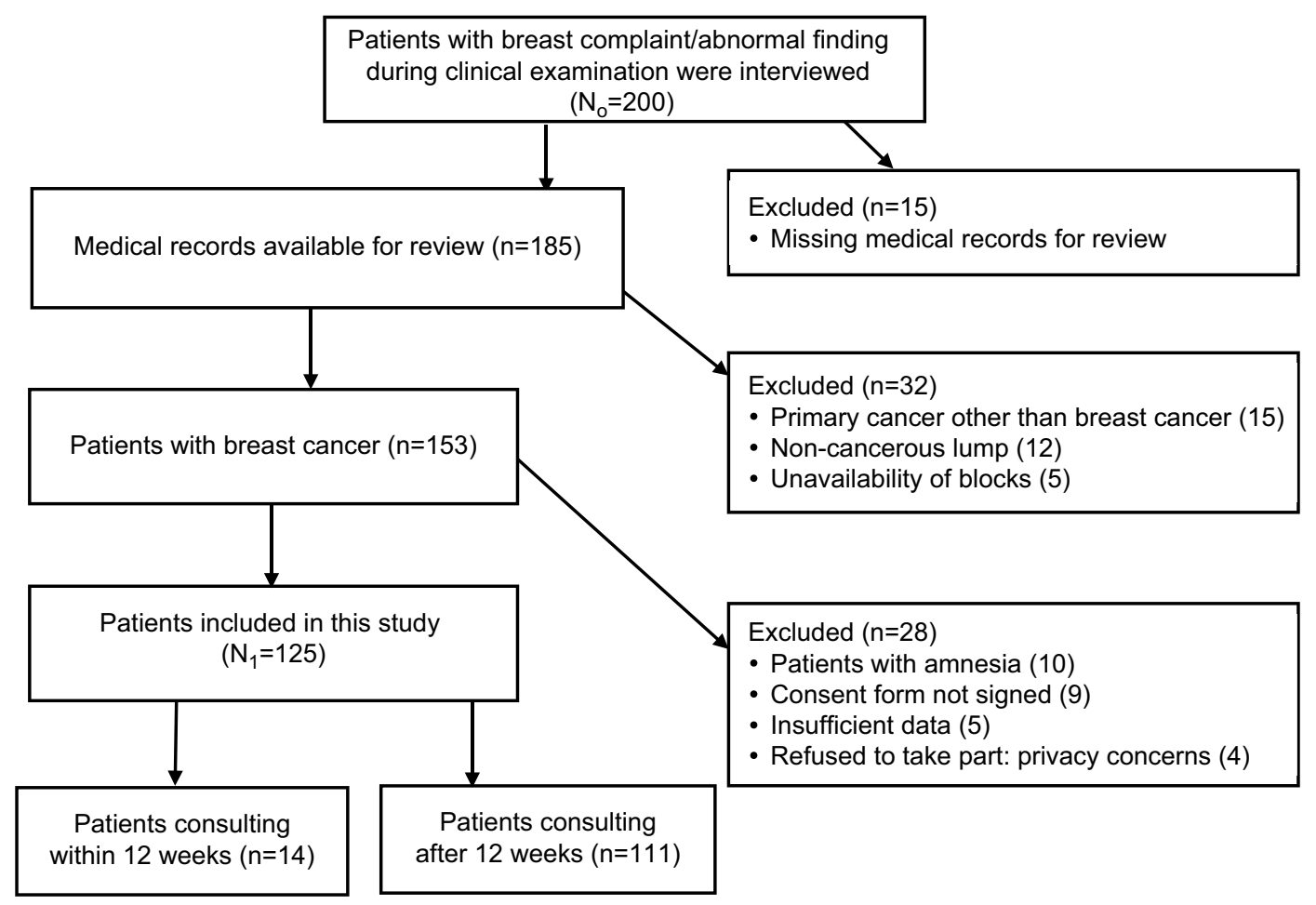

Figure I Flow diagram of the patients included in this study.

Abbreviations: $\mathrm{N}_{0}$, Patients included at the start of the study; $\mathrm{N}_{1}$, data on the patients analyzed and presented in this study. 
metastatic carcinoma $(n=15)$, presence of non-cancerous lumps $(n=12)$, unavailability of tissue sample or blocks $(n=5)$, amnesia $(n=10)$, refusal to sign the consent owing to privacy concerns $(n=9)$, incomplete responses to questions $(n=5)$ and refusal to participate at any stage of the interview $(n=4)$, as summarized in Figure 1. Finally, data from 125 patients were analyzed and are presented in this study.

\section{Participants' characteristics}

The mean age of the participants was $44.1 \pm 9.91$ years, with a range of 24-75 years. The majority were aged more than 40 years $(65.6 \%)$, had less than 8 years of education (60.8\%), and married (99.2\%), and 84 patients $(67.2 \%)$ had poor socioeconomic status ( $<$ Pakistani rupee 5,000/month). Eighty-one patients $(64.8 \%)$ had a negative family history of cancer while $37(29.6 \%)$ had a positive family history of breast cancer. Fifty-one patients (41\%) presented with stage II cancer and $74(59 \%)$ presented at an advanced stage of the disease i.e. III and IV (Table 1).

\section{Presenting symptoms}

Table 2 shows the initial breast cancer symptoms experienced by patients before they sought any medical help. Patients often presented with more than one symptom; the most common clinical symptom was the presence of a painless breast lump (in $81.1 \%$ ), with variable localities such as a knot in the armpit (4.2\%) and painful breast lumps (2.8\%).
Four women $(3.2 \%)$ had complained of nipple discharge or a change in the shape of their breast. Only $2.1 \%$ women complained about redness or swelling of the breast skin, such as a peau d'orange modification or mastitis-like onset.

\section{Presentation delay}

Only 14 patients $(11.2 \%)$ had consulted a doctor within 3 months of developing breast cancer symptoms, while 111 patients $(89.8 \%)$ had approached the physician after more than 3 months. Out of these 111, 22 patients $(17.6 \%)$ had sought help from a doctor within 6 months, 48 (38.4\%) had consulted within 12 months and the remaining 41 (32.8\%) had consulted more than 12 months after the appearance of symptoms. The numbers of patients with each duration of delay in consultation are shown in Figure 2.

\section{Knowledge about risk factors of breast cancer}

Table 3 summarizes the patients' knowledge regarding the breast cancer risk factors. Our patients scored 4.5 out of a maximum score of 17 . One-hundred (80\%), 92 (73.6\%) and 84 patients $(67.2 \%)$ did not know that parity age, early menarche and late menopause, respectively, are associated with breast cancer. In addition, 76 patients $(60.8 \%)$ considered breastfeeding as a risk factor for breast cancer. They also failed to identify most of the risk factors, ie, previous breast cancer, obesity, smoking, drinking, oral contraceptives and gender.

Table I Sociodemographic data of selected patients and studied variables

\begin{tabular}{|c|c|c|c|}
\hline Variable & Category & Patients (n) & Patients (\%) \\
\hline \multirow[t]{2}{*}{ Age at diagnosis } & $<40$ years & 43 & 34.4 \\
\hline & $\geq 40$ years & 82 & 65.6 \\
\hline \multirow[t]{2}{*}{ Education } & $<8$ years & 76 & 60.8 \\
\hline & $\geq 8$ years & 49 & 39.2 \\
\hline \multirow[t]{2}{*}{ Marital status } & Married & 124 & 99.2 \\
\hline & Single & 1 & 0.8 \\
\hline \multirow[t]{2}{*}{ Socioeconomic status } & $<$ PKR 5,000/month & 84 & 67.2 \\
\hline & $\geq$ PKR 5,000/month & 41 & 32.8 \\
\hline \multirow[t]{2}{*}{ Residence } & Rural & 62 & 49.6 \\
\hline & Urban & 63 & 50.4 \\
\hline \multirow[t]{2}{*}{ Menopausal status } & Pre-menopausal & 70 & 56 \\
\hline & Post-menopausal & 55 & 44 \\
\hline \multirow[t]{2}{*}{ Tumor location } & Left breast & 63 & 50.4 \\
\hline & Right breast & 62 & 49.6 \\
\hline \multirow[t]{3}{*}{ Disease stage } & II & 51 & 40.8 \\
\hline & III & 73 & 58.4 \\
\hline & IV & 1 & 0.8 \\
\hline \multirow[t]{2}{*}{ Family history of any cancer } & No one & 81 & 64.8 \\
\hline & At least one person & 44 & 35.2 \\
\hline \multirow[t]{2}{*}{ Family history of breast cancer } & No one & 88 & 70.4 \\
\hline & At least one person & 37 & 29.6 \\
\hline
\end{tabular}

Abbreviation: PKR, Pakistani rupee. 
Table 2 Frequency of patients with presenting symptoms and duration of presentation delay

\begin{tabular}{|c|c|c|c|}
\hline Symptom & Patients, n (\%) & Delay $<3$ months & Delay $\geq 3$ months \\
\hline Painless lump in breast & $116(92.8 \%)$ & $12(85.7 \%)$ & $104(93.7 \%)$ \\
\hline Lump in armpit & $6(4.8 \%)$ & $\mathrm{I}(7.1 \%)$ & $5(4.5 \%)$ \\
\hline Change in breast shape & $4(3.2 \%)$ & $2(14.2 .1 \%)$ & $2(1.8 \%)$ \\
\hline Nipple discharge & $4(3.2 \%)$ & I (7.I\%) & $3(2.7 \%)$ \\
\hline Painful lump in breast & $4(3.2 \%)$ & $0(0 \%)$ & $4(3.6 \%)$ \\
\hline Redness/swelling over breast & $3(2.4 \%)$ & $\mathrm{I}(7.1 \%)$ & $2(1.8 \%)$ \\
\hline Pain in arm or back & $2(1.6 \%)$ & $\mathrm{I}(7.1 \%)$ & $\mathrm{I}(0.9 \%)$ \\
\hline Bone pain & $2(1.6 \%)$ & $0(0 \%)$ & $2(1.8 \%)$ \\
\hline Ulcer over breast & $\mathrm{I}(0.8 \%)$ & $0(0 \%)$ & I $(0.9 \%)$ \\
\hline Weakness & $\mathrm{I}(0.8 \%)$ & $0(0 \%)$ & $\mathrm{I}(0.9 \%)$ \\
\hline Total & $\mathrm{N}=125$ & $n=14$ & $n=11 \mid$ \\
\hline
\end{tabular}

Note: Patients often presented with more than one symptom, so column totals do not add up to $100 \%$.

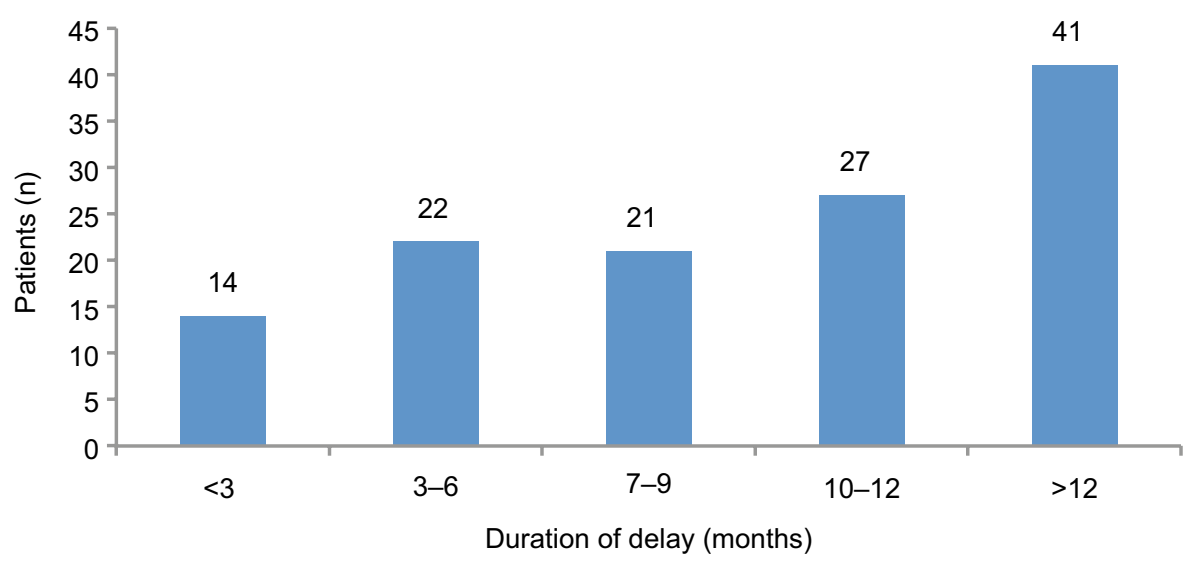

Figure 2 Distribution of patients according to the duration of delay before consulting a physician.

Table 3 Assessment of patients' knowledge about breast cancer risk factors

\begin{tabular}{|c|c|c|c|}
\hline \multirow[t]{2}{*}{ Risk factor variable } & \multicolumn{3}{|c|}{ Patients ( $\mathrm{N}=125), \mathrm{n}(\%)$} \\
\hline & Yes & No & I do not know \\
\hline Age & $31(24.8)$ & $41(32.8)$ & $53(42.4)$ \\
\hline Gender & $34(27.2)$ & $29(23.2)$ & $62(49.6)$ \\
\hline Early menarche & $9(7.2)$ & $24(19.2)$ & $92(73.6)$ \\
\hline Late menopause & $12(9.6)$ & $29(23.2)$ & $84(67.2)$ \\
\hline Parity age & II (8.8) & $14(11.2)$ & $100(80)$ \\
\hline Trauma & $41(32.8)$ & $35(28)$ & $49(39.2)$ \\
\hline Stress & $21(16.8)$ & $78(62.4)$ & $26(20.8)$ \\
\hline Oral contraceptives & $38(30.4)$ & $16(12.8)$ & $71(56.8)$ \\
\hline Obesity & $19(15.2)$ & $29(23.2)$ & $77(61.6)$ \\
\hline Family history & $7 \mid(56.8)$ & $21(16.8)$ & $33(26.4)$ \\
\hline Overweight & $33(26.4)$ & $31(24.8)$ & $61(48.8)$ \\
\hline Breastfeeding & $76(60.8)$ & $32(25.6)$ & $17(13.6)$ \\
\hline Smoking & $4 \mathrm{I}(32.8)$ & $20(16)$ & $64(5 \mid .2)$ \\
\hline Drinking & $42(33.6)$ & $21(16.8)$ & $62(49.6)$ \\
\hline Pollution & $44(35.2)$ & $31(24.8)$ & $50(40)$ \\
\hline Previous breast cancer & $13(10.4)$ & $17(13.6)$ & $95(76)$ \\
\hline Radiation & $30(24)$ & $22(17.6)$ & $73(58.4)$ \\
\hline
\end{tabular}

\section{Reasons for late presentation}

The reasons given by participants for delayed presentation were as follows: in 107 patients (96\%), presentation delay was due to ignorance of disease or the presence of a painless lump in the breast; 90 patients (81\%) reported a fear of the cost of anticipated treatment; 81 (73\%) informed us that they were shy about being attended by a male doctor and $79(71 \%)$ presented late because of the prior use of herbal or unconventional treatments. Seventy-two participants (65\%) were scared about cancer-associated stigma, or isolation from their husband, family and friends, or felt hesitant about undergoing surgical procedures, $68(61 \%)$ had consulted spiritual healers or believed themselves to have been spiritually healed, and $41(37 \%)$ presented late owing to other reasons (eg, "clinic/ hospital was too far away", "too busy” or "didn't want anyone to know that I had a lump"). These proportions were not mutually exclusive, as represented in Figure 3. 


\section{Factors associated with presentation delay}

Non-significant associations were observed between the studied variables and patient delay, including the age at diagnosis, menopausal status, tumor location, and positive family history of cancer and breast cancer. Educational status and residential status were significantly $(P<0.001)$ associated with delayed presentation. Delayed presentation due to the women's marital and economic status was also significant $(P<0.05)$, as summarized in Table 4. Binary regression confirmed the association between presentation delay and educational level, with an OR of $4.682(P<0.001)$. Similar results were obtained for the economic status of patients and presentation delay (OR $1.875,95 \%$ CI $59.006-1.875 ; P=0.007)$. No association was found for other variables, ie, patient age, residence, positive family history of cancer or breast cancer, menopausal status and tumor location (Table 5).

\section{Discussion}

Our results have revealed that breast cancer patients are facing major problems in Pakistan in terms of presentation delay that is one of the leading causes of mortality in women. In this study, $88.8 \%$ cases of breast cancer presented after a delay ( $>3$ months) and $93.7 \%$ of these women had painless lumps in their breast. The presence of a lump upon examination may indicate a lack of aware- ness and knowledge about disease symptoms and disease screening programs. This can lead to aggressive disease and ultimately yield lower survival rates. Another study, conducted in a developing country in Middle-East Asia (Jordan), highlighted that $94.7 \%$ of asymptomatic patients were diagnosed with breast cancer after a medical examination. Breast cancer due to late presentation has also been shown in other studies. ${ }^{28-32}$ All of these outcomes were due to the late presentation, as observed in our study.

We have highlighted several parameters that were responsible for delayed presentation in breast cancer patients. Many variables were identified as being due to a limited level of education, which was a significant factor in the univariate analysis. Most of the Pakistani population has low living standards and they are unable to afford the high educational costs of academic institutes. Moreover, the illiterate population lacks awareness about the disease, its signs and symptoms and its treatment plans. There is an assumption among the public that a person suffering from any sort of carcinoma has zero chance of survival and there is no treatment available for the cancer. So, a lack of awareness and a lack of education are the key factors contributing to late presentation for breast cancer and enhanced mortality. ${ }^{32-35}$ In underdeveloped and developing countries, including Pakistan, it is necessary to segregate high-risk patients due to the delayed presentation so that new and implementable strategies can be designed to resolve this issue.

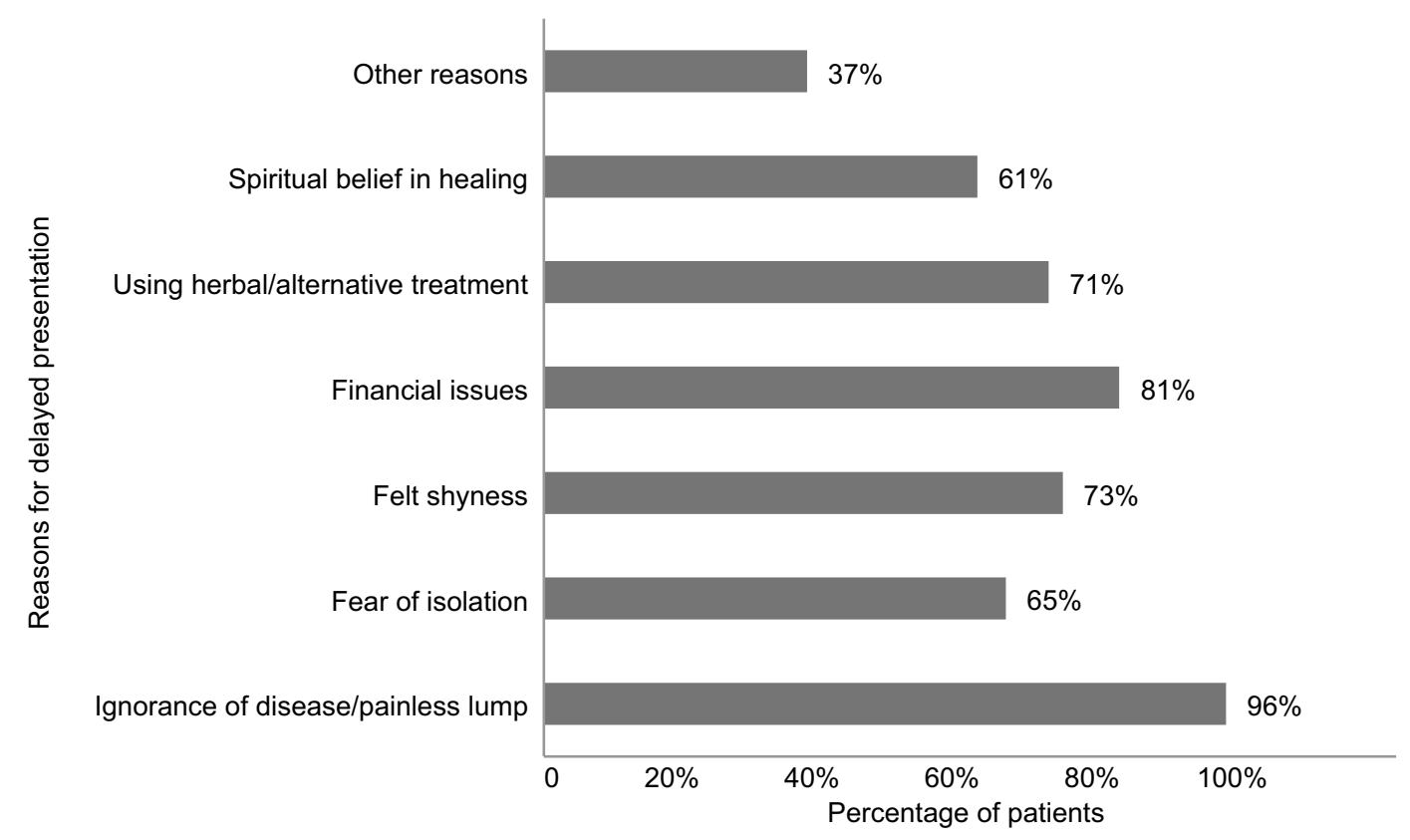

Figure 3 Percentage of patients with reasons for delayed presentation.

Note: Patients highlighted more than one barrier to presentation, so the totals do not add up to $100 \%$. 
Table 4 Sociodemographic factors and their association with presentation delay

\begin{tabular}{|c|c|c|c|c|}
\hline \multirow[t]{2}{*}{ Variable } & \multirow[t]{2}{*}{ Category } & \multicolumn{2}{|c|}{ Time of presentation, $\mathbf{n}(\%)$} & \multirow[t]{2}{*}{$P$-value ${ }^{a}$} \\
\hline & & $<3$ months & $\geq 3$ months & \\
\hline \multirow[t]{2}{*}{ Age at diagnosis } & $<40$ years & $4(9.3 \%)$ & $39(90.7 \%)$ & \multirow[t]{2}{*}{0.078} \\
\hline & $\geq 40$ years & $18(22.0 \%)$ & $64(78.0 \%)$ & \\
\hline \multirow[t]{2}{*}{ Education } & $<8$ years & $3(3.9 \%)$ & $73(96.1 \%)$ & \multirow[t]{2}{*}{$<0.00 I^{* *}$} \\
\hline & $\geq 8$ years & $19(38.8 \%)$ & $30(6 \mid .2 \%)$ & \\
\hline \multirow[t]{2}{*}{ Marital status } & Married & $21(16.9 \%)$ & $103(83.1 \%)$ & \multirow[t]{2}{*}{$0.03 *$} \\
\hline & Single & $\mathrm{I}(\mathrm{I} 00 \%)$ & $0(0 \%)$ & \\
\hline \multirow[t]{2}{*}{ Socioeconomic status } & $<$ PKR 5,000/month & $19(22.6 \%)$ & $65(77.4 \%)$ & \multirow[t]{2}{*}{$0.035^{*}$} \\
\hline & $\geq$ PKR 5,000/month & $3(7.3 \%)$ & $38(92.7 \%)$ & \\
\hline \multirow[t]{2}{*}{ Residence } & Rural & $5(8.1 \%)$ & 57 (91.9\%) & \multirow[t]{2}{*}{$0.005 * *$} \\
\hline & Urban & $17(27.0 \%)$ & $46(73.0 \%)$ & \\
\hline \multirow[t]{2}{*}{ Menopausal status } & Pre-menopausal & $13(18.6 \%)$ & $57(81.4 \%)$ & \multirow[t]{2}{*}{0.748} \\
\hline & Post-menopausal & $9(16.4 \%)$ & $46(83.6 \%)$ & \\
\hline \multirow[t]{2}{*}{ Tumor location } & Left breast & $8(12.7 \%)$ & $55(87.3 \%)$ & \multirow[t]{2}{*}{0.147} \\
\hline & Right breast & $14(22.6 \%)$ & $48(77.4 \%)$ & \\
\hline \multirow[t]{2}{*}{ Family history of any cancer } & No one & $13(16.0 \%)$ & $68(84.0 \%)$ & \multirow[t]{2}{*}{0.537} \\
\hline & At least one person & $9(20.5 \%)$ & 35 (79.5\%) & \\
\hline \multirow[t]{2}{*}{ Family history of breast cancer } & No one & $16(18.2 \%)$ & $72(81.8 \%)$ & \multirow[t]{2}{*}{0.792} \\
\hline & At least one person & $6(16.2 \%)$ & $31(83.8 \%)$ & \\
\hline
\end{tabular}

Note: aChi-squared test: $* P \leq 0.05$ and $* * P \leq 0.001$ indicate statistical significance.

Abbreviation: PKR, Pakistani rupee.

Table 5 Logistic regression analysis showing odds ratios and confidence intervals for the studied variables

\begin{tabular}{|c|c|c|c|c|c|c|}
\hline \multirow[t]{2}{*}{ Variable } & \multirow[t]{2}{*}{ Category } & \multicolumn{2}{|c|}{ Delay in diagnosis, $\mathbf{n}(\%)$} & \multicolumn{3}{|c|}{ Binary analysis } \\
\hline & & $<3$ months & $\geq 3$ months & OR & $95 \% \mathrm{Cl}$ & $P$-value \\
\hline \multirow[t]{2}{*}{ Age at diagnosis } & $<40$ years & $4(9.3 \%)$ & $39(90.7 \%)$ & 0.043 & $0.912-0.043$ & 0.038 \\
\hline & $\geq 40$ years & $18(22.0 \%)$ & $64(78.0 \%)$ & & & \\
\hline \multirow[t]{2}{*}{ Education } & $<8$ years & $3(3.9 \%)$ & $73(96.1 \%)$ & 4.682 & - & $<0.001$ \\
\hline & $\geq 8$ years & $19(38.8 \%)$ & $30(61.2 \%)$ & & & \\
\hline \multirow[t]{2}{*}{ Marital status } & Married & $21(16.9 \%)$ & $103(83.1 \%)$ & 0.000 & 0.000 & 1.000 \\
\hline & Single & $\mathrm{I}(100 \%)$ & $0(0 \%)$ & & & \\
\hline \multirow{2}{*}{$\begin{array}{l}\text { Socioeconomic } \\
\text { status }\end{array}$} & $<$ PKR 5,000/month & $19(22.6 \%)$ & $65(77.4 \%)$ & 1.875 & $59.006-1.875$ & 0.007 \\
\hline & $\geq$ PKR 5,000/month & $3(7.3 \%)$ & $38(92.7 \%)$ & & & \\
\hline \multirow[t]{2}{*}{ Residence } & Rural & $5(8.1 \%)$ & 57 (91.9\%) & 0.062 & $0.70 \mathrm{I}-0.062$ & 0.011 \\
\hline & Urban & $17(27.0 \%)$ & $46(73.0 \%)$ & & & \\
\hline \multirow[t]{2}{*}{ Menopausal status } & Pre-menopausal & $13(18.6 \%)$ & 57 (8I.4\%) & 0.371 & $4.909-0.371$ & 0.649 \\
\hline & Post-menopausal & $9(16.4 \%)$ & $46(83.6 \%)$ & & & \\
\hline \multirow[t]{2}{*}{ Tumor location } & Left breast & $8(12.7 \%)$ & $55(87.3 \%)$ & 0.117 & $1.224-0.117$ & 0.105 \\
\hline & Right breast & $14(22.6 \%)$ & $48(77.4 \%)$ & & & \\
\hline \multirow{2}{*}{$\begin{array}{l}\text { Family history of } \\
\text { any cancer }\end{array}$} & No one & $13(16.0 \%)$ & $68(84.0 \%)$ & 0.028 & $1.46 \mathrm{I}-0.028$ & 0.113 \\
\hline & At least one person & $9(20.5 \%)$ & 35 (79.5\%) & & & \\
\hline \multirow{2}{*}{$\begin{array}{l}\text { Family history of } \\
\text { breast cancer }\end{array}$} & No one & $16(18.2 \%)$ & $72(81.8 \%)$ & 0.529 & $28.095-0.529$ & 0.183 \\
\hline & At least one person & $6(16.2 \%)$ & $31(83.8 \%)$ & & & \\
\hline
\end{tabular}

Note: The "-" symbol in the table indicates data not shown due to the low number of patients within $<3$ month range for delay in diagnosis.

Abbreviation: PKR, Pakistani rupee.

In a prospective, multicenter, cohort study conducted in the USA, among women with recently diagnosed breast cancer of less than 40 years, $17 \%$ reported a self-delay associated with poor financial status. ${ }^{36}$ Paradoxical results have been observed in less affluent societies. In a cross-sectional study conducted in Thailand, 180 women with invasive breast cancer were interviewed about potential risk factors and causes of delayed presentation. The results showed that $17 \%$ of delays in seeking consultation for longer than 3 months were associated with higher family income and smoking. ${ }^{37}$ This may be explained by less attention being paid to healthrelated problems; nevertheless, this is an example of complex interactions between psychosocial and cognitive factors which cannot be fully explained with simple assumptions.

It was also identified in the present study that breast cancer was more prevalent among married women in the studied population (99.2\%). Because of social taboos, women with breast cancer feel embarrassment and shyness when discuss- 
ing breast-health concerns. Cultural barriers cause married woman to have less access to caregivers and poor orientation towards attending targeted health units alone because they are dependent on their husbands or heads of the family. ${ }^{38}$ Most of them $(72 \%)$ rely on alternative medicines for treatment and they habitually skip doses. Thereby, not seeking prompt attention for breast problems and seeking medical care from "quacks", rather than an oncologist, was related to a diagnosis of advanced breast cancer. Moreover, a married woman has a lot of work to do regarding her responsibilities to her family. ${ }^{39}$

Most of the Pakistani population lives in rural areas that are lacking in basic necessities such as hospitals, education systems, transport, purified drinking water, hygienic conditions and trained and qualified healthcare providers. ${ }^{24}$ Therefore, the chances of delayed presentation are higher in rural than in urban populations. Moreover, social norms, poverty, misconceptions, false beliefs about disease, lack of education awareness about the disease and its management may be the leading factors resulting in delayed presentation in this region. ${ }^{40-45}$

In this investigation, $96 \%$ of the studied population $(n=107)$ presented with a delay due to a lack of information about symptoms, indicating progression of the disease along with pathological changes in the form of painless lumps. Enlargement of a lump is an alarming indication of cancer, which may prompt a patient to consult a doctor. These factors arise owing to low levels of education, and poor social and economic status..$^{24,40,41,46}$ Continuously growing lumps, at a slower rate, may grab less attention in the suffering person. In this case, slight delay in presentation can leads to poor recovery. Based on this, one can propose that late-stage tumors and a delayed diagnosis are the predisposing factors associated with the lowest survival chances. ${ }^{47}$

In Pakistan, the healthcare system generally focuses on patients, medicines, prescribers and customers, instead of encouraging people to disclose disorders that are symptomatically and asymptomatically progressing, namely raising awareness. This is due to the low levels of routine medical examinations, high consultation fees and lack of counseling time provided by caregivers. Over the past few years, the public health department, cancer hospitals and teaching institutes have initiated an awareness program about breast cancer, supported by national and international non-governmental organizations (NGOs). It aims to counsel the public about consequences, symptomatic profile, risk factors, diagnostic techniques and treatment options. This awareness program is executed via electronic and print media, and seminars organized on world breast cancer day. However, few hospitals have joined the initiative to establish an early-detection service for timely breast cancer diagnosis. These initiatives are running under the name "Breast Clinic Day" in hospitals working under the umbrella of the PAEC. Through these awareness programs, women will be made aware of simple, self-inspection methods to check for tumors, so that they can seek health care as early as possible. The Government of Pakistan health department has a rich resource of personnel including nurses, female medical officers and health visitors, who perform their duties in rural health centers, basic health units, tehsil headquarters, district headquarters and combined military hospitals. Nurses, female medical officers and health visitors are the right choice if training is given and they are used for the stated purpose. This strategy will be a revolutionary step in the early diagnosis of breast cancer in Pakistan. Ultimately, it will improve survival rates and reduce cases of mortality.

\section{Limitations of the study}

The present study had a small sample size compared to the large number of breast cancer patients in the Pakistani population, and was limited to breast cancer patients who visited PINUM hospital in Faisalabad. Therefore, there may have been a bias in the data related to the regional and background characteristics of the patients. So, similar studies must be conducted in other hospitals in Pakistan to find out the key reasons for delayed presentation. Continual awareness campaigns should be scheduled for awareness in rural as well as urban areas of Pakistan. Minimal charges or free-of-cost screening facilities must be provided by the collaborative action of the Government of Pakistan and other NGOs working nationally or internationally in Pakistan.

\section{Conclusion}

A significant percentage of women with breast cancer in Pakistan delay presentation because of their misconceptions and false beliefs about the disease and its management. Failure to understand breast cancer symptoms is a risk factor for delayed presentation. Coordinated efforts are needed from the public health department regarding awareness about breast cancer, its signs and symptoms, risk factors and therapeutic outcomes, to educate the focus groups and remove the barriers identified in the study. Improving symptom recognition to facilitate prompt presentation in this population may improve survival. In the long run, these efforts should result in an increased survival rate and reduced overall burden of the disease in Pakistan.

This study demonstrates the importance of providing interventions and strategies to increase the awareness of breast cancer in Pakistan. One of the roots of the problem is the existence of stigma and financial constraints, representing social and economic barriers to the timely diagnosis and 
treatment of breast cancer patients. Early diagnosis and early recognition of breast symptoms in primary health care, along with an accessible and affordable referral path for care, can save lives; it is the most powerful and validated way to impact on the population with a reasonable investment in public health. Accordingly, this study has identified the gaps and the possible areas for intervention, providing evidence to build a population-based early diagnosis program to be framed within the national cancer control plan.

\section{Ethical approval and consent to participate}

The present work was reviewed and approved by the Ethical Committee of the National Institute for Biotechnology and Genetic Engineering (NIBGE), Faisalabad, Pakistan (reference number 102/14), and signed by each participant or family member.

\section{Acknowledgments}

The authors thank the Higher Education Commission (HEC) of Pakistan for providing financial assistance in the form of an indigenous $\mathrm{PhD}$ scholarship (grant number 112-241292BM1-229). We are grateful to all the participants and PINUM staff for their cooperation. We are also obliged to Dr Barbara Burmen, senior research officer at the Kenya Medical Research Institute Center for Global Health Research Kisumu, Kenya, and Dr Asif Mahmood, Assistant Professor at the Faculty of Pharmacy, The University of Lahore, Lahore, Pakistan, for their guidance and help in reviewing and editing this manuscript. An abstract of this paper was presented at the World Cancer Congress as an abstract presentation with interim findings between the $1^{\text {st }}-4^{\text {th }}$ October, 2018, Kuala Lumpur, Malaysia. The poster's abstract has been published. ${ }^{48}$

\section{Disclosure}

The authors report no conflicts of interest in this work.

\section{References}

1. Bray F, Ferlay J, Soerjomataram I, Siegel RL, Torre LA, Jemal A. Global cancer statistics 2018: GLOBOCAN estimates of incidence and mortality worldwide for 36 cancers in 185 countries. CA Cancer J Clin. 2018;68(6):394-424.

2. Ferlay J, Steliarova-Foucher E, Lortet-Tieulent J, et al. Cancer incidence and mortality patterns in Europe: estimates for 40 countries in 2012. Eur J Cancer. 2013;49(6):1374-1403.

3. Ferlay J, Soerjomataram I, Dikshit R, et al. Cancer incidence and mortality worldwide: sources, methods and major patterns in GLOBOCAN 2012. Int J Cancer. 2015;136(5):E359-E386.

4. Boyle P, Levin B, editors. World Cancer Report 2008. Lyon: IARC Press; 2008.

5. Ferlay J, Soerjomataram I, Ervik M, et al, editors. GLOBOCAN 2012: estimated cancer incidence, mortality and prevalence worldwide in 2012. Lyon: IARC Press; 2012.
6. Stewart BW, Wild CP, editors. World Cancer Report 2014. Lyon: IARC Press; 2014.

7. Vineis P, Wild CP. Global cancer patterns: causes and prevention. Lancet. 2014;383(9916):549-557.

8. Jamal S, Atique M, Khadim MT. Changing pattern of malignancies: analysis of histopathology based tumour registry data and comparison of three decades at Armed Forces Institute of Pathology, Rawalpindi, Pakistan. J Pak Med Assoc. 2014;64(1):24-27.

9. Torre LA, Bray F, Siegel RL, Ferlay J, Lortet-Tieulent J, Jemal A. Global cancer statistics, 2012. CA Cancer J Clin. 2015;65(2):87-108.

10. Luzzati T, Parenti A, Rughi T. Economic growth and cancer incidence. Ecol Econ. 2018;146:381-396.

11. Colditz GA, Bohlke K. Priorities for the primary prevention of breast cancer. CA Cancer J Clin. 2014;64(3):186-194.

12. Shahab L, McGowan JA, Waller J, Smith SG. Prevalence of beliefs about actual and mythical causes of cancer and their association with sociodemographic and health-related characteristics: findings from a cross-sectional survey in England. Eur J Cancer. 2018;103:308-316.

13. Khan RT, Siddique A, Shahid N, Khokher S, Fatima W. Breast cancer risk associated with genes encoding DNA repair MRN complex: a study from Punjab, Pakistan. Breast Cancer. 2018;25(3):350-355.

14. Mahmood S, Rana TF, Ahmad M. Common determinants of $\mathrm{Ca}$ breast - a case control study in Lahore. Ann King Edward Med Univ. 2006;12(2):227-228.

15. Butt Z, Haider SF, Arif S. Breast cancer risk factors: a comparison between pre-menopausal and post-menopausal women. J Pak Med Assoc. 2012;62(2):120.

16. Asif HM, Sultana S, Akhtar N, Rehman JU, Rehman RU. Prevalence, risk factors and disease knowledge of breast cancer in Pakistan. Asian Pac J Cancer Prev. 2014;15(11):4411-4416.

17. Majeed AI, Jadoon M, Riazuddin S, Akram J. Awareness and screening of breast cancer among rural areas of Islamabad capital territory, Pakistan. Ann Pak Inst Med Sci. 2017;13(1):103-107.

18. Sarwar MR, Saqib A. Cancer prevalence, incidence and mortality rates in Pakistan in 2012. Cogent Med. 2017;4(1):1288773.

19. Baloch AH, Shuja J, Daud S, et al. Various aspects, patterns and risk factors in breast cancer patients of Balochistan. Asian Pac J Cancer Prev. 2012;13(8):4013-4016.

20. Ibrahim NA, Oludara MA. Socio-demographic factors and reasons associated with delay in breast cancer presentation: a study in Nigerian women. Breast. 2012;21(3):416-418.

21. Sharma K, Costas A, Damuse R, et al. The Haiti breast cancer initiative: initial findings and analysis of barriers-to-care delaying patient presentation. J Oncol. 2013;2013:206367.

22. Richards MA, Smith P, Ramirez AJ, Fentiman IS, Rubens RD. The influence on survival of delay in the presentation and treatment of symptomatic breast cancer. Br J Cancer. 1999;79(5-6):858-864.

23. Khokher S, Qureshi MU, Mahmood S, Sadiq S. Determinants of advanced stage at initial diagnosis of breast cancer in Pakistan: adverse tumor biology vs delay in diagnosis. Asian Pac J Cancer Prev. 2016;17(2):759-765.

24. Khan N, Ahmad R, Nadeem M, Hussain I. Influence of education and socio-economic factors on stage of cancer diagnosis: a study in Pakistani population. Ann Pak Inst Med Sci. 2016;12(4):225-229.

25. Bureau of Statistics, Pakistan. District and tehsil level population summary with region breakup. Available from: http://www.pbscensus.gov. pk/sites/default/files/bwpsr/punjab/FAISLABAD_SUMMARY.pdf. Accessed July 16, 2018.

26. Raosoft. Sample size calculator; 2015. Available from: http://www. raosoft.com/samplesize.html. Accessed July 16, 2018.

27. Faul F, Erdfelder E, Lang AG, Buchner A. G*Power 3: a flexible statistical power analysis program for the social, behavioral, and biomedical sciences. Behav Res Methods. 2007;39(2):175-191.

28. Innos K, Padrik P, Valvere V, et al. Identifying women at risk for delayed presentation of breast cancer: a cross-sectional study in Estonia. BMC Public Health. 2013;13(1):947.

29. O’Mahony M, McCarthy G, Corcoran P, Hegarty J. Shedding light on women's help seeking behaviour for self discovered breast symptoms. Eur J Oncol Nurs. 2013;17(5):632-639. 
30. Brzozowska A, Duma D, Mazurkiewicz T, Brzozowski W, Mazurkiewicz M. [Reasons for delay in treatment of breast cancer detected due to breast self-examination in women from the Lubelskie region]. Ginekol Pol. 2014;85(1):14-17.

31. Jones CE, Maben J, Jack RH, et al. A systematic review of barriers to early presentation and diagnosis with breast cancer among black women. BMJ Open. 2014;4(2):e004076.

32. Khan MA, Hanif S, Iqbal S, Shahzad MF, Shafique S, Khan MT. Presentation delay in breast cancer patients and its association with sociodemographic factors in North Pakistan. Chin J Cancer Res. 2015;27(3):288.

33. Opoku SY, Benwell M, Yarney J. Knowledge, attitudes, beliefs, behaviour and breast cancer screening practices in Ghana, West Africa. Pan African Med J. 2012;11:28.

34. Pruitt L, Mumuni T, Raikhel E, et al. Social barriers to diagnosis and treatment of breast cancer in patients presenting at a teaching hospital in Ibadan, Nigeria. Glob Public Health. 2015;10(3):331-344.

35. Pace LE, Mpunga T, Hategekimana V, et al. Delays in breast cancer presentation and diagnosis at two rural cancer referral centers in Rwanda. Oncologist. 2015;20(7):780-788.

36. Ruddy KJ, Gelber S, Tamimi RM, et al. Breast cancer presentation and diagnostic delays in young women. Cancer. 2014;120(1):20-25.

37. Poum A, Promthet S, Duffy SW, Parkin DM. Factors associated with delayed diagnosis of breast cancer in northeast Thailand. J Epidemiol. 2014;24(2):102-108.

38. Rehman H, Moazzam A, Ansari N. Role of microfinance institutions in women empowerment: a casestudy of Akhuwat, Pakistan. South Asian Stud. 2015;30(1):107.

39. Khan MA, Ahmed M, Ahmed N. Treatment navigation pathway and barriers to treatment for cancer patients in Khyber Pakhtunkhwa, Pakistan. J Med Sci. 2017;25(2):209-212.
40. Macdonald S, Macleod U, Campbell NC, Weller D, Mitchell E. Systematic review of factors influencing patient and practitioner delay in diagnosis of upper gastrointestinal cancer. $\mathrm{Br} J$ Cancer. 2006;94(9):1272-1280.

41. Bish A, Ramirez A, Burgess C, Hunter M. Understanding why women delay in seeking help for breast cancer symptoms. J Psychosom Res. 2005;58(4):321-326.

42. Mitchell E, Macdonald S, Campbell NC, Weller D, Macleod U. Influences on pre-hospital delay in the diagnosis of colorectal cancer: a systematic review. Br J Cancer. 2008;98(1):60-70.

43. McLachlan S, Mansell G, Sanders T, et al. Symptom perceptions and help-seeking behaviour prior to lung and colorectal cancer diagnoses: a qualitative study. Fam Pract. 2015;32(5):568-577.

44. Ouasmani F, Hanchi Z, Haddou Rahou B, Bekkali R, Ahid S, Mesfioui A. Determinants of patient delay in seeking diagnosis and treatment among Moroccan women with cervical cancer. Obstet Gynecol Int. 2016; 2016:9.

45. Macleod U, Mitchell ED, Burgess C, Macdonald S, Ramirez AJ. Risk factors for delayed presentation and referral of symptomatic cancer: evidence for common cancers. Br J Cancer. 2009;101(S2): S92-S101.

46. Forbes LJ, Warburton F, Richards MA, Ramirez AJ. Risk factors for delay in symptomatic presentation: a survey of cancer patients. $\mathrm{Br} J$ Cancer. 2014;111(3):581-588.

47. Caplan L. Delay in breast cancer: implications for stage at diagnosis and survival. Front Public Health. 2014;2:87.

48. Gulzar F. Identifying the barriers of delayed presentation in Pakistani breast cancer patients undergoing care at tertiary hospital. J Glob Oncol. 2018;4(Supp1 2):215s.
Cancer Management and Research

\section{Publish your work in this journal}

Cancer Management and Research is an international, peer-reviewed open access journal focusing on cancer research and the optimal use of preventative and integrated treatment interventions to achieve improved outcomes, enhanced survival and quality of life for the cancer patient. The manuscript management system is completely online and includes

\section{Dovepress}

a very quick and fair peer-review system, which is all easy to use. Visit http://www.dovepress.com/testimonials.php to read real quotes from published authors. 